\title{
Three-dimensional personnel safety positioning based on improved UKF under complex coal mine environment
}

\author{
Hongxiang X $u^{1}$, Xingzhen Bai ${ }^{1}$, Lujie Zhou ${ }^{2,3^{*}}$, and Peng Liu ${ }^{1}$ \\ 1 College of Electrical Engineering and Automation, Shandong University of Science and Technology, \\ Qingdao, Shandong 266590, China; \\ 2 State Key Laboratory of Mining Disaster Prevention and Control Co-founded by Shandong Province \\ and the Ministry of Science and Technology, Shandong University of Science and Technology, Qingdao \\ 266590, China; \\ 3 College of Safety and Environmental Engineering, Shandong University of Science and Technology, \\ Qingdao 266590, China
}

\begin{abstract}
Aiming at the problems of strong interference and poor positioning accuracy in coal mines, this paper proposes a positioning algorithm for accurate detection of personnel safety. It is of great practical significance to detect the safety movement track of underground personnel. In this paper, WSNs distributed in coal mines are divided into several clusters by clustering method. Each cluster has a certain number of sensors, which can communicate with each other to keep the estimation consistency, and send the collected data to the cluster head $(\mathrm{CH})$ node. System noise includes additive noise and multiplicative noise. In order to improve the accuracy of estimation, an improved UKF algorithm is proposed. The simulation results show that the improved UKF algorithm improves the accuracy and performance of estimation, and allows better location of the underground personnel.
\end{abstract}

\section{Introduction}

Coal resources are the driving force of economic development ${ }^{[1]}$. To ensure the efficient and safe production of coal industry is a very concerned issue of the state and relevant departments ${ }^{[1-5]}$. There are many miners who are engaged in coal mining under the harsh and dangerous environment ${ }^{[3]}$. The coal mining conditions are poor, and disasters such as gas, water, fire, dust, high temperature occur frequently, which seriously threaten the safety of miners, leading to the coal industry becoming a high-risk industry. In order to ensure the safety of coal mine underground personnel, it is necessary to accurately locate the space and track of underground personnel ${ }^{[4]}$. However, the underground coal mine is a completely closed space, without the assistance of satellite navigation signal. It is very difficult to realize the positioning and navigation of personnel.

* Corresponding author: $\underline{\text { skd995954@,sdust.edu.cn }}$ 
In the past, the way of wire communication was used to locate the personnel in the coal mine, which had some defects such as complicated wiring, high cost and strong dependence on the line ${ }^{[6]}$. In [7], radio frequency identification (RFID) technology is proposed. The technology has played a positive role in reducing coal mine safety accidents. However, the underground positioning system based on RFID technology relies on wired transmission system, which greatly limits the expansion of network scale. In [8], a coal mine underground positioning system based on wireless sensor networks (WSNs) is adopted. A typical WSNs is composed of a group of special sensors with spatial distribution. Each sensor shares information on the network and completes complex work together ${ }^{[9]}$. When the number of sensors is large, each sensor will transmit data to the fusion center, which will cause a waste of resources ${ }^{[10-14]}$. An improved method is to divide the spatially distributed sensors into multiple clusters. Each cluster has a certain number of sensors, the sensors send data to the cluster head $(\mathrm{CH})$ node, and the sensors nodes can communicate with each other, so as to ensure the consistency and accuracy of the estimation ${ }^{[15-18]}$.

In the complex environment of coal mine, filtering technology has been widely used. In [19], a positioning method of mine personnel based on Kalman filter (KF) is proposed. By weighting the measurement results and prediction results reasonably, the best estimation value at the current time can be obtained according to the best estimation value after KF in the previous step, so as to realize the accurate positioning of mine personnel. In nonlinear filtering, we often use extended Kalman filter (EKF) algorithm and unscented Kalman filter (UKF) algorithm ${ }^{[20-22]}$. In [20], an EKF algorithm based on event triggering is proposed. However, EKF algorithm has many defects in accuracy and stability. EKF omits higher-order terms, and Jacobian matrix must also be calculated. UKF is a nonparametric nonlinear filtering algorithm, which has been widely used in the field of secure location in recent years. In [22], an improved UKF algorithm with limited communication bandwidth is proposed, only part of the measured output can be transmitted to the remote estimator.

Based on the above analysis, this paper adopts an improved UKF algorithm based on three-dimensional underground personnel safety positioning. Considering the complex interference problem in coal mine environment, an improved UKF algorithm with event triggering is proposed to improve the positioning accuracy and solve the complex interference problem.

\section{Problem Description}

Safety positioning of underground personnel is one of the applications of WSNs. A large number of micro sensor nodes are deployed in the monitoring area to transmit and detect data through wireless communication. Fig. 1 shows the position movement of the underground coal mine roadway and the sensor distribution.

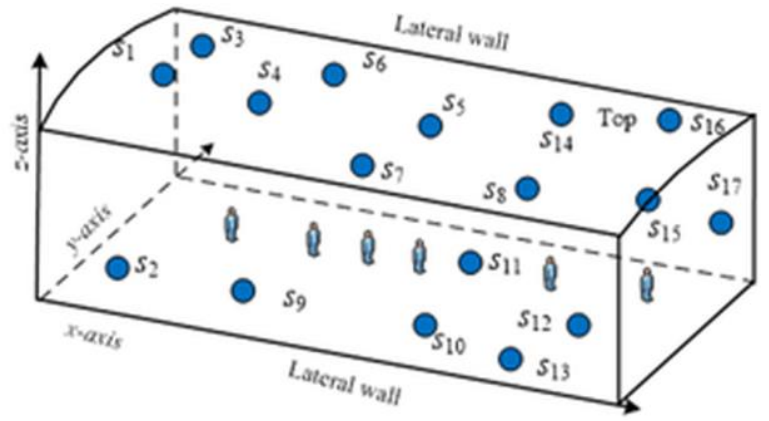

Fig. 1. Position movement of underground personnel and sensor distribution 


\subsection{System Model}

We consider a safety positioning system of coal mine based on wireless network. In the threedimensional space, it is assumed that the movement model of underground personnel can be expressed as:

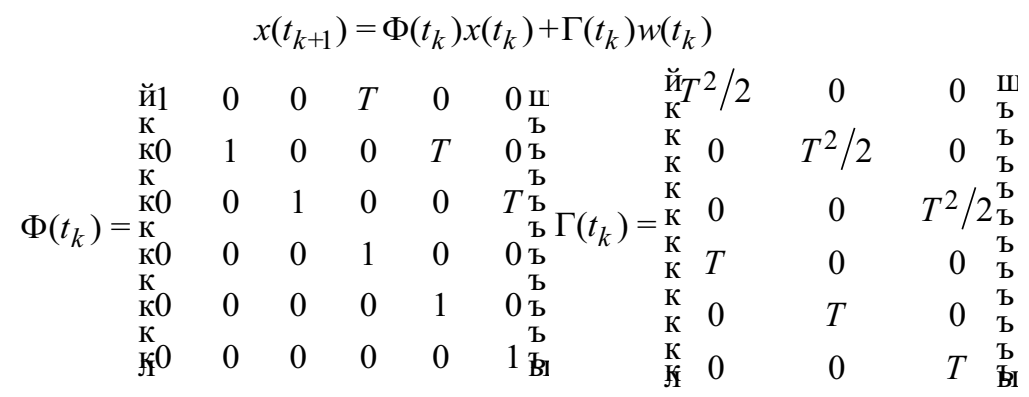

where $\Phi\left(t_{k}\right)$ and $\Gamma\left(t_{k}\right)$ are known matrices of appropriate dimensions, and $w\left(t_{k}\right) \mathrm{O} R^{m}$ is zero mean Gaussian white noise, which is expressed as follows:

$$
w\left(t_{k}\right)=\left[w^{x}\left(t_{k}\right), w^{y}\left(t_{k}\right), w^{z}\left(t_{k}\right)\right]^{T}
$$

where $t_{k}$ is the sampling interval. Suppose there are $M$ clusters and $m$ sensors. The cluster set is expressed as $Z_{0}=\{1,2, \ldots, M\}$. In the sensor network, there are several sensors used to detect the location of underground people, and the measurement model is shown as follows:

$$
\begin{aligned}
& y_{r, i}\left(t_{k}\right)=h\left(x_{r, i}\left(t_{k}\right)\right)+v_{r, i}\left(t_{k}\right), r \mathrm{O} Z_{0}, \quad i=1,2, \ldots, m \\
& h\left(x_{r, i}\left(t_{k}\right)\right)=\sqrt{\left(x_{p, r, i}\left(t_{k}\right)-P_{r, i, x}\right)+\left(y_{p, r, i}\left(t_{k}\right)-P_{r, i, y}\right)+\left(z_{p, r, i}\left(t_{k}\right)-P_{r, i, z}\right)}
\end{aligned}
$$

where $y_{r, i}\left(t_{k}\right)$ is the measured value of the sensor. $h\left(x_{r, i}\left(t_{k}\right)\right)$ is the expression of the nonlinear measurement equation. $x_{p, r, i}\left(t_{k}\right), y_{p, r, i}\left(t_{k}\right)$ and $z_{p, r, i}\left(t_{k}\right)$ represent the coordinates of underground personnel. $P_{r, i, x}, P_{r, i, y}$ and $P_{r, i, z}$ represent the coordinates of the sensor. $w\left(t_{k}\right)$ and $v_{r, i}\left(t_{k}\right)$ are zero-mean Gaussian noise sequences that are mutually uncorrelated with initial state $x_{0}$. The following are statistical properties of $x_{0}$, $w\left(t_{k}\right)$ and $v_{r, i}\left(t_{k}\right)$ :

$$
\begin{aligned}
& E\left(x_{0}\right)=\hat{x}_{0}, E\left\{\left(x_{0}-\hat{x}_{0}\right)\left(x_{0}-\hat{x}_{0}\right)^{T}=\hat{P}_{0}\right. \\
& E\left(w\left(t_{k}\right)\right)=0, E\left(w\left(t_{k}\right) w^{T}\left(t_{k}\right)\right)=Q\left(t_{k}\right) \\
& E\left(v_{r, i}\left(t_{k}\right)\right)=0, E\left(v_{r, i}\left(t_{k}\right) v_{r, i}^{T}\left(t_{k}\right)\right)=R_{r, i}\left(t_{k}\right)
\end{aligned}
$$

\subsection{Complex Interference Conditions in Coal Mine}

In the underground environment of coal mine, due to the sudden change of environment and the failure of random actuator, there may be interference problems in the modeling process. The actual model of underground personnel under complex interference conditions is as follows:

$$
x\left(t_{k+1}\right)=\Phi\left(t_{k}\right) x\left(t_{k}\right)+\mathrm{A}\left(t_{k}\right) x\left(t_{k}\right)+\Gamma\left(t_{k}\right) w\left(t_{k}\right)
$$

where $\mathrm{A}\left(t_{k}\right) x\left(t_{k}\right)$ is regarded as a part of process noise. A new process noise $\zeta\left(t_{k}\right)$ is 
defined, and satisfies:

$$
\begin{gathered}
\zeta\left(t_{k}\right)=\mathrm{A}\left(t_{k}\right) x\left(t_{k}\right)+\Gamma\left(t_{k}\right) w\left(t_{k}\right) \\
E\left[\zeta\left(t_{k}\right)\right]=0 \\
E\left[\zeta\left(t_{k}\right) \zeta\left(t_{k}\right)^{T}\right]=Q^{*}\left(t_{k}\right)
\end{gathered}
$$

The location model of underground personnel including complex interference problems is as follows:

$$
\begin{aligned}
& x\left(t_{k+1}\right)=\Phi\left(t_{k}\right) x\left(t_{k}\right)+\zeta\left(t_{k}\right) \\
& y_{r, i}\left(t_{k}\right)=h\left(x_{r, i}\left(t_{k}\right)\right)+v_{r, i}\left(t_{k}\right)
\end{aligned}
$$

\section{The improved UKF algorithm under the complex interference conditions}

\subsection{Unscented Transformation}

Unscented transformation (UT) is a method of approximate nonlinear transformation probability distribution. Under the assumption that the independent variable is Gaussian distribution, the mean and covariance of the dependent variable can be used for approximation. $2 n+1$ sigma point are as follows:

$$
\begin{aligned}
& { }_{\Pi}^{\mathrm{M}} \chi_{0}\left(t_{k-1} \mid t_{k-1}\right)=\hat{x}_{r, i}\left(t_{k-1} \mid t_{k-1}\right) \\
& { }_{\mathrm{H}}^{\mathrm{H}} \chi_{r, i}\left(t_{k-1} \mid t_{k-1}\right)=\hat{x}_{r, i}\left(t_{k-1} \mid t_{k-1}\right)+\left(\sqrt{(n+\lambda) \hat{P}_{r, i}\left(t_{k-1} \mid t_{k-1}\right)}\right)_{j} \quad j=1, \ldots, n \\
& { }_{\mathrm{B}}^{\Pi} \chi_{r, i}\left(t_{k-1} \mid t_{k-1}\right)=\hat{x}_{r, i}\left(t_{k-1} \mid t_{k-1}\right)-\left(\sqrt{(n+\lambda) \hat{P}_{r, i}\left(t_{k-1} \mid t_{k-1}\right)}\right)_{j} \quad j=n+1, \ldots, 2 n
\end{aligned}
$$

where $j=0,1, \ldots, 2 n, n$ is the dimension of the state. $\chi_{r, i}\left(t_{k-1} \mid t_{k-1}\right)$ is the sigma point. $\left(\sqrt{(n+\lambda) \hat{P}_{r, i}\left(t_{k-1} \mid t_{k-1}\right)}\right)_{j}$ represents the $j$ th column of the square root of positive definite matrix $\left(\sqrt{(n+\lambda) \hat{P}_{r, i}\left(t_{k-1} \mid t_{k-1}\right)}\right)$ in the sense of Cholesky decomposition. $\lambda=\alpha^{2}(n+\kappa)-n$, $\alpha$ and $\kappa$ are two adjustable parameters. $\kappa \mathrm{i} 0,0 \mathrm{~J} \alpha \mathrm{J} 1, \lambda$ is a scalable scale parameter. The weighting coefficients are given as.

$$
\begin{aligned}
& \underset{\Pi}{\mathrm{M}} \omega_{\mathrm{H}}^{(0)}=\frac{\lambda}{n+\lambda}, \quad j=0 \\
& { }_{\mathrm{O}}^{\mathrm{\Pi}} \omega^{\mathrm{H}}(j)=\frac{1}{2(n+\lambda)}, \quad j=1, \ldots, 2 n
\end{aligned}
$$

After getting the sigma points and weight coefficients, it is necessary to propagate each sigma point, and generate a set of sigma points $\hat{\chi}_{r, i}\left(t_{k} \mid t_{k-1}\right)$ as follows:

$$
\hat{\chi}_{r, i}\left(t_{k} \mid t_{k-1}\right)=\Phi\left(t_{k}\right) \chi_{r, i}\left(t_{k-1} \mid t_{k-1}\right)
$$

The state prediction $\hat{x}_{r, i}\left(t_{k} \mid t_{k-1}\right)$ is obtained by weighting the transformed sigma points.

$$
\hat{x}_{r, i}\left(t_{k} \mid t_{k-1}\right)=\mathrm{e}_{j=0}^{2 n} \omega^{(j)} \hat{\chi}_{r, i}\left(t_{k} \mid t_{k-1}\right)
$$

The error value and prediction error covariance are as follows: 


$$
\begin{gathered}
\tilde{x}_{r, i}\left(t_{k} \mid t_{k-1}\right)=\hat{\gamma}_{r, i}\left(t_{k} \mid t_{k-1}\right)-\hat{x}_{r, i}\left(t_{k} \mid t_{k-1}\right) \\
P_{x x}^{r, i}\left(t_{k} \mid t_{k-1}\right)=\mathrm{e}_{j=0}^{2 n} \omega(j) \tilde{x}_{r, i}\left(t_{k} \mid t_{k-1}\right) \Gamma \tilde{x}_{r, i}^{T}\left(t_{k} \mid t_{k-1}\right)+\Gamma\left(t_{k}\right) Q\left(t_{k}\right) \Gamma^{T}\left(t_{k}\right)
\end{gathered}
$$

\subsection{Personnel Safety Positioning in Coal Mine based on Improved UKF Algorithm}

Considering the interference problem in the complex environment of coal mine, the interference noise is regarded as a part of the process noise, and the event triggering mechanism is added to improve the accuracy of estimation. Fig. 2 shows the improved UKF algorithm flow chart. $\mathrm{A}\left(t_{k}\right) x\left(t_{k}\right)$ is regarded as a part of the process noise. The new process noise $\zeta\left(t_{k}\right)$ includes $\mathrm{A}\left(t_{k}\right) x\left(t_{k}\right)$ and $\Gamma\left(t_{k}\right) w\left(t_{k}\right)$. Formula (16) can be modified as follows:

$$
P_{x x}^{r, i}\left(t_{k} \mid t_{k-1}\right)=\mathrm{e}_{j=0}^{2 n} \omega^{(j)} \tilde{x}_{r, i}\left(t_{k} \mid t_{k-1}\right) \Gamma \tilde{x}_{r, i}^{T}\left(t_{k} \mid t_{k-1}\right)+Q^{*}\left(t_{k}\right)
$$

where $Q^{*}\left(t_{k}\right)$ is the covariance matrix under the condition of complex interference. $P_{x x}^{r, i}\left(t_{k} \mid t_{k-1}\right)$ represents the one-step prediction error covariance at time $t_{k}$.

$$
\begin{gathered}
\hat{y}_{r, i}^{\chi}\left(t_{k} \mid t_{k-1}\right)=h\left(\hat{x}_{r, i}\left(t_{k} \mid t_{k-1}\right)\right) \\
\hat{y}_{r, i}\left(t_{k} \mid t_{k-1}\right)=\mathrm{e}_{j=0}^{2 n} \omega^{(j)} \hat{y}_{r, i}^{\chi}\left(t_{k} \mid t_{k-1}\right)
\end{gathered}
$$

where $\hat{y}_{r, i}^{\chi}\left(t_{k} \mid t_{k-1}\right)$ represents the measured predicted value of sigma point. $\hat{y}_{r, i}\left(t_{k} \mid t_{k-1}\right)$ represents the predicted value after weighted, and the measured predicted covariance matrix is as follows:

$$
\begin{aligned}
& \left.P_{y y^{\prime}}^{r, t_{k}} \mid t_{k-1}\right)=\mathrm{e}_{j=0}^{2 n} \omega^{(j)} \tilde{y}_{r, i}\left(t_{k} \mid t_{k-1}\right) \mathrm{r} \hat{y}_{r, i}^{T}\left(t_{k} \mid t_{k-1}\right)+R_{r, i}\left(t_{k}\right) \\
& \hat{y}_{r, i}\left(t_{k} \mid t_{k-1}\right)=\hat{y}_{r, i}^{\gamma}\left(t_{k} \mid t_{k-1}\right)-\hat{y}_{r, i}\left(t_{k} \mid t_{k-1}\right)
\end{aligned}
$$

The cross-covariance matrix is as follows:

$$
P_{x y}^{r, i}\left(t_{k} \mid t_{k-1}\right)=\mathrm{e}_{j=0}^{2 n} \omega^{(j)} \tilde{x}_{r, i}\left(t_{k} \mid t_{k-1}\right) \mathrm{r} \hat{j}_{r, i}^{T}\left(t_{k} \mid t_{k-1}\right)
$$

Calculate the gain of UKF.

$$
K_{r, i}=P_{x y}^{r, i}\left(t_{k} \mid t_{k-1}\right)\left(P_{y y}^{r, i}\left(t_{k} \mid t_{k-1}\right)\right)^{-1}
$$

In order to improve the energy utilization and reduce the transmission of measured values, an event triggered sensor scheduling strategy is proposed ${ }^{[20]}$. When the trigger condition is met, the sensor sends the measured value $y_{r, i}\left(t_{k}\right)$; otherwise, it does not send. For the sensor, the calculation energy consumption is far lower than the transmission energy consumption. 
Therefore, the event triggering mechanism can reduce the energy consumption of the sensor and extend the service life of the intelligent sensor. The event trigger condition is as follows:

$$
\begin{aligned}
\bar{\pi}_{r, i}\left(t_{k}\right)= & \underset{\mathrm{H}}{\mathrm{M}} 1, i f\left(y_{r, i}\left(t_{k}\right)-\bar{y}_{r, i}\left(t_{k}\right)\right)\left(y_{r, i}\left(t_{k}\right)-\bar{y}_{r, i}\left(t_{k-1}\right)\right)^{T}>\delta_{r, i} \\
& \quad \text { O others }
\end{aligned}
$$

where $\bar{y}_{r, i}\left(t_{k-1}\right)$ is the latest measurement value successfully sent by the sensor. $y_{r, i}\left(t_{k}\right)$ is the measurement value of the current time, and $\delta_{r, i}$ is the predetermined trigger threshold. For subsequent developments, the current transmitted measurement $\bar{y}_{r, i}\left(t_{k}\right)$ is defined as:

$$
\bar{y}_{r, i}\left(t_{k}\right)=\bar{\lambda}_{r, i}\left(t_{k}\right) y_{r, i}\left(t_{k}\right)+\left(1-\bar{\lambda}_{r, i}\left(t_{k}\right)\right) \bar{y}_{r, i}\left(t_{k-1}\right), \bar{\lambda}_{r, i}\left(t_{k}\right) O[0,1]
$$

Calculate the estimated value and the corresponding estimation error covariance are as follows.

$$
\begin{aligned}
\hat{x}_{r, i}\left(t_{k} \mid t_{k}\right) & =\hat{x}_{r, i}\left(t_{k} \mid t_{k-1}\right)+K_{r, i} \mathrm{r}\left[\bar{y}_{r, i}\left(t_{k}\right)-\hat{y}_{r, i}\left(t_{k} \mid t_{k-1}\right)\right] \\
& =\hat{x}_{r, i}\left(t_{k} \mid t_{k-1}\right)+K_{r, i} \mathrm{r}\left[\bar{\lambda}_{r, i}\left(t_{k}\right) y_{r, i}\left(t_{k}\right)\right. \\
& \left.+\left(1-\bar{\pi}_{r, i}\left(t_{k}\right)\right) \bar{y}_{r, i}\left(t_{k-1}\right)-\hat{y}_{r, i}\left(t_{k} \mid t_{k-1}\right)\right] \\
P_{r, i}\left(t_{k} \mid t_{k}\right)= & P_{x x}^{r, i}\left(t_{k} \mid t_{k-1}\right)-K_{r, i} \mathrm{r} P_{y y}^{r, i}\left(t_{k} \mid t_{k-1}\right) K_{r, i}^{T}
\end{aligned}
$$

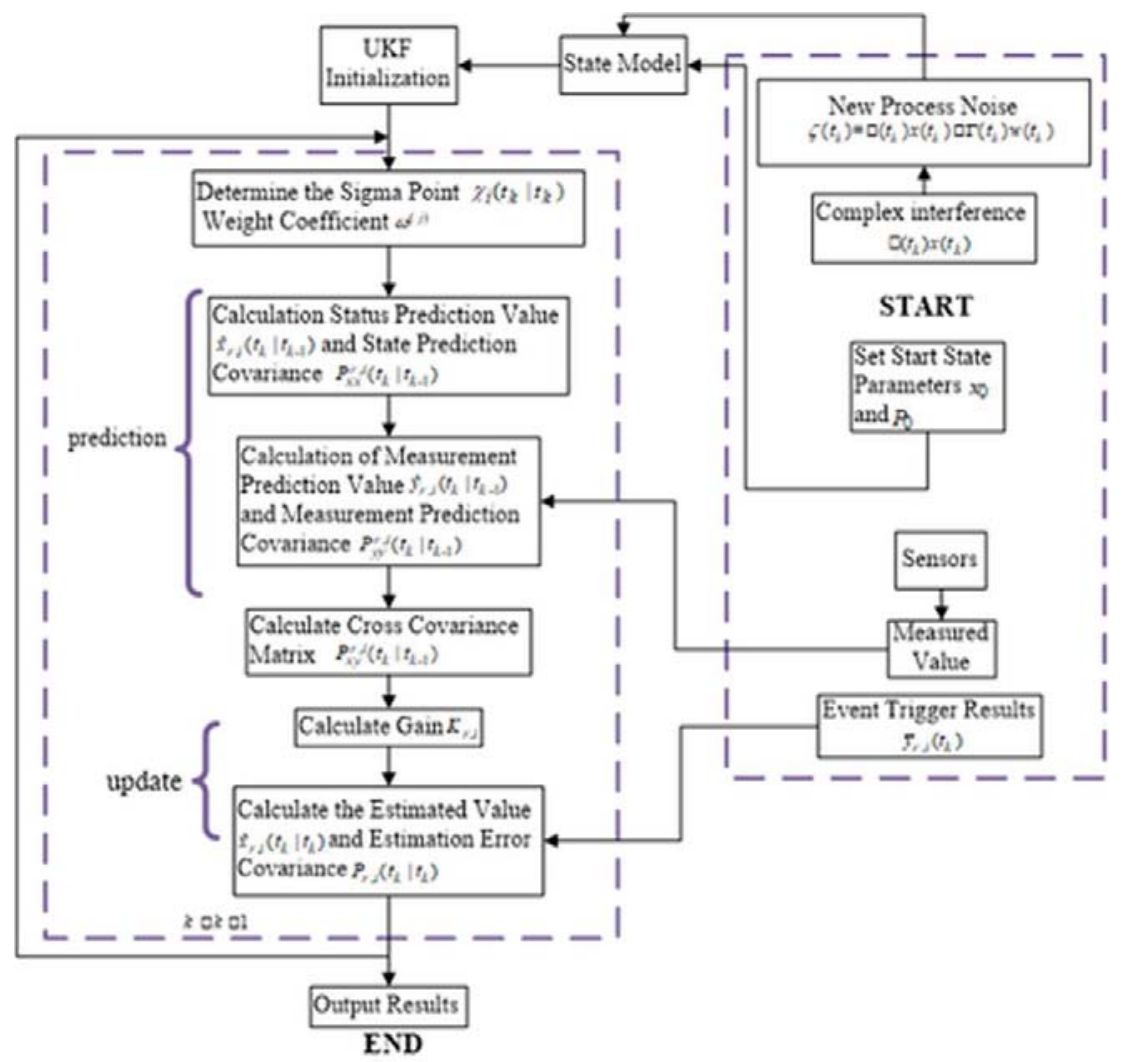

Fig. 2. Flow chart of improved UKF algorithm 


\section{Simulation}

This paper assumes that in a 40-meter-long, 4-meter-wide and 4-meter-high coal mine roadway, the miners advance at a speed of $1 \mathrm{~m} / \mathrm{s}$, and the miners advance at a certain speed. Set the covariance matrix of measurement and state noise as $Q\left(t_{k}\right)=10^{-3} \Gamma \operatorname{diag}([5,1,1])$ and $R_{r, i}\left(t_{k}\right)=0.1$. Sensor nodes are distributed on the side and top of the coal mine. The sensors are divided into four clusters, each cluster has five sensors. The sensors in the cluster can communicate with each other to keep the estimation consistent. Fig. 3 and Fig. 4 are node distribution and clustering diagram of WSNs in coal mine roadway.

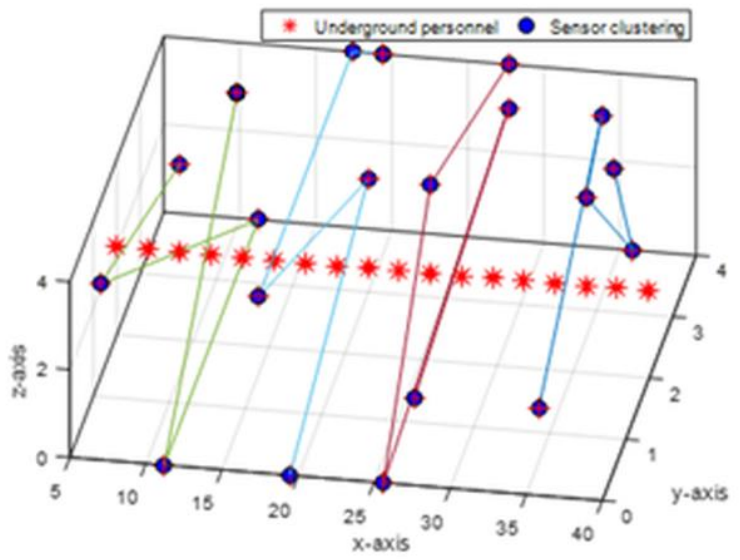

Fig. 3. Node distribution of WSNs

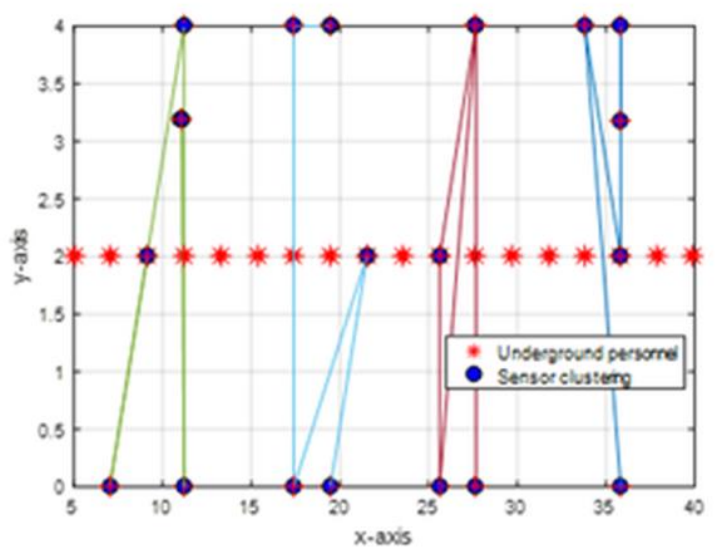

Fig. 4. Top view of node distribution of WSNs 

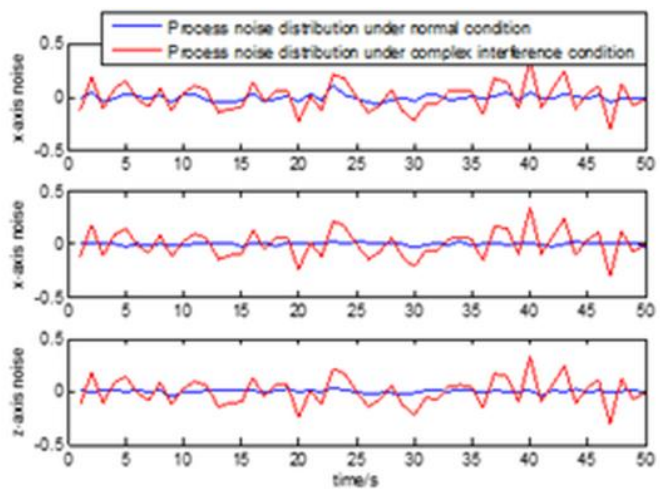

Fig. 5. Noise distribution

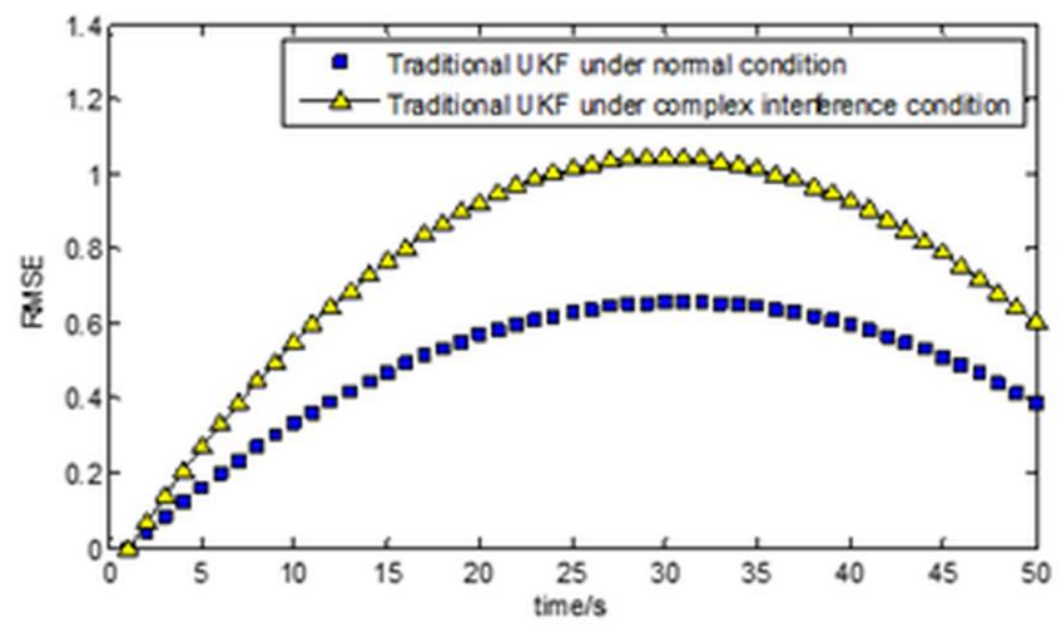

Fig. 6. RMSE comparison under normal condition and under complex interference condition

Considering the complex interference in the coal mine environment, Fig. 5 shows the noise distribution of the sensor. It can be seen from the figure that the noise distribution under normal conditions is different from that under abnormal conditions, and the noise fluctuates greatly under random interference environment. Fig. 6 is a comparison of the traditional UKF algorithm under normal and complex interference conditions. It can be seen from the figure that the accuracy of the filter is relatively small under the condition of complex interference. 

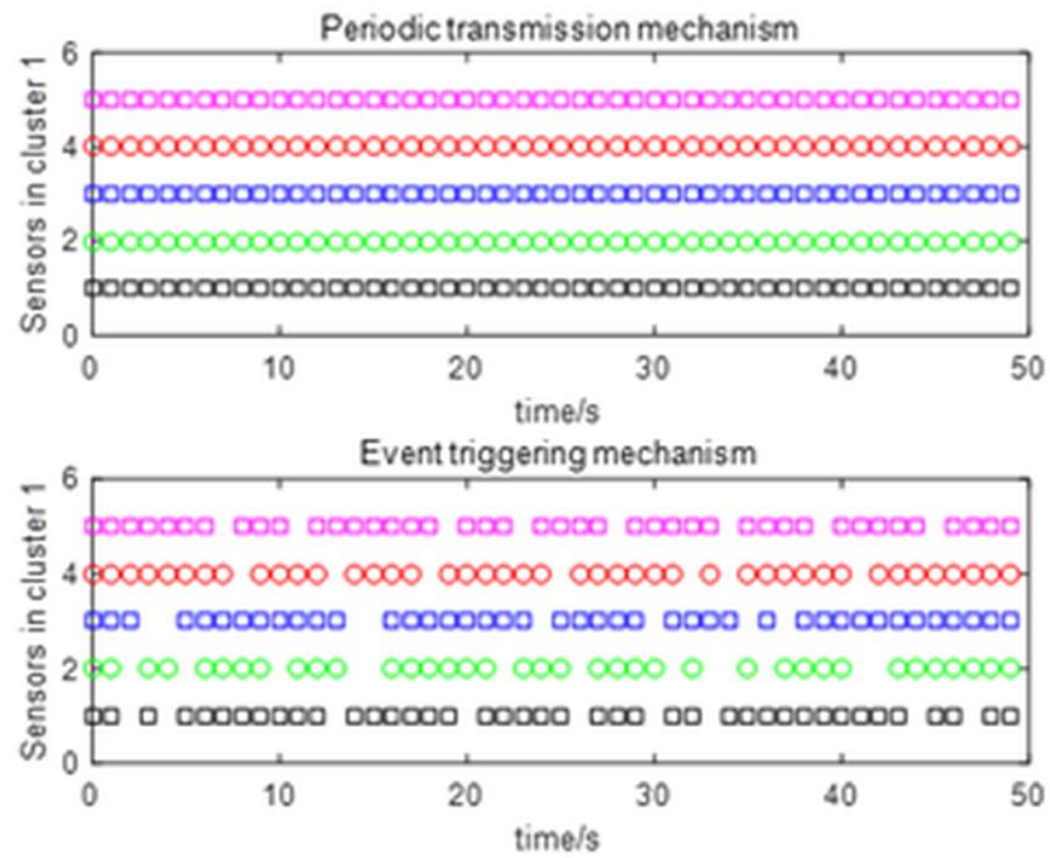

Fig. 7. Comparison between periodic transmission and event triggered transmission interval

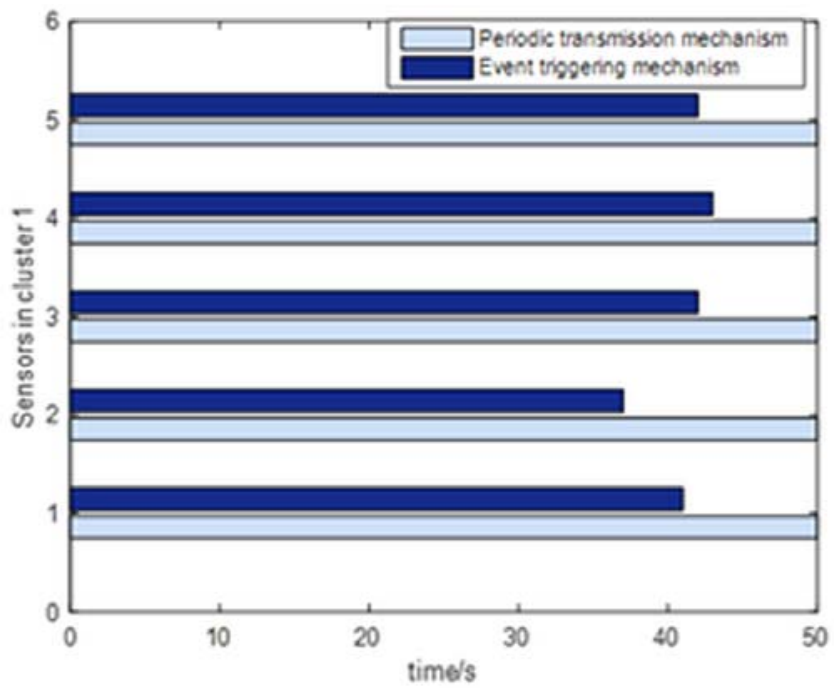

Fig. 8. Number of transmitted data packets on sensor (in different cases of the periodic transport mechanism and the event triggered transport mechanism) 


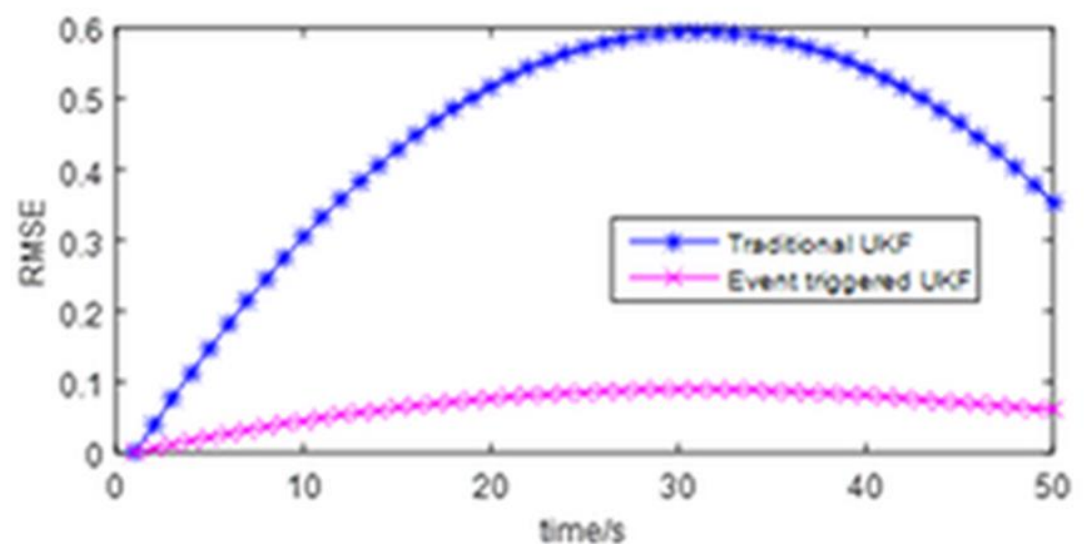

Fig. 9. UKF algorithm comparison under periodic transmission mechanism and event triggered transmission mechanism

In order to save energy, the event triggering mechanism is adopted. Fig. 7 and Fig. 8 show the comparison diagram of periodic transmission and event triggering. As can be seen from the figure, event triggering can reduce the number of data transfers and save more energy. Fig. 9 shows the comparison of UKF algorithm in the case of periodic transmission and event triggered transmission. It can be seen from the figure that under the event triggered mechanism, the accuracy of the algorithm is higher and the effect is more obvious.

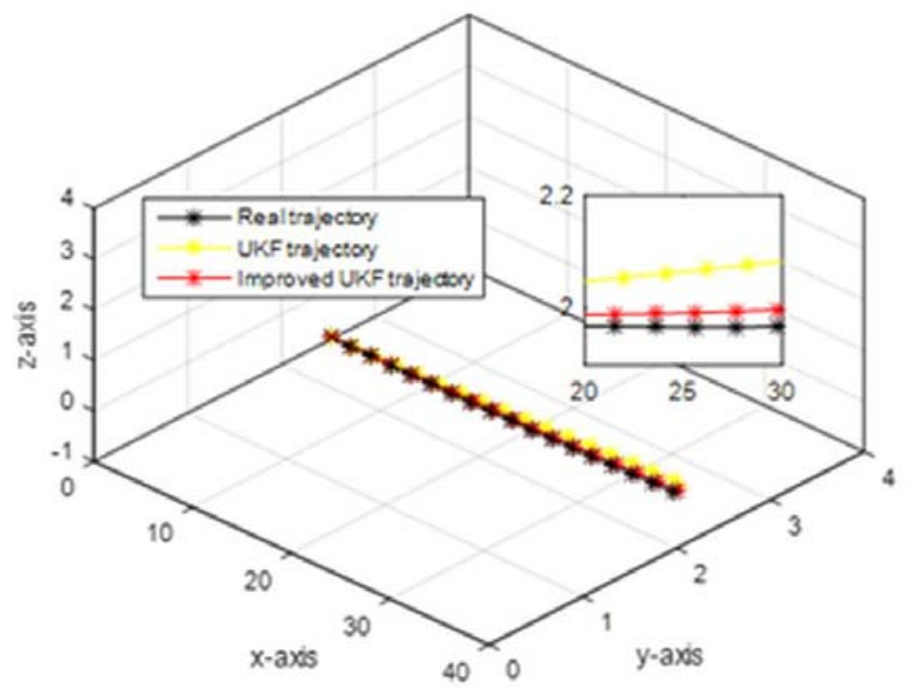

Fig. 10. Comparison of real trajectory 、 traditional UKF and improved UKF trajectory 


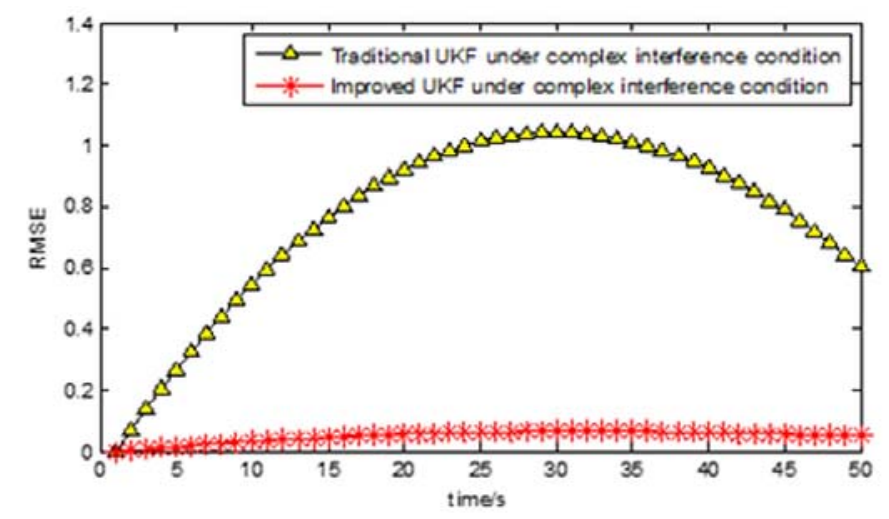

Fig. 11. RMSE comparison between improved UKF and traditional UKF under interference condition

Fig. 10 shows the comparison of the real trajectory, UKF filtering and improved UKF filtering trajectory of underground personnel movement. It can be seen from the figure that the estimated trajectory obtained by the improved UKF algorithm is closer to the real trajectory. Fig. 11 shows the RMSE comparison between the improved UKF algorithm and traditional UKF. The simulation results show that the improved UKF algorithm has smaller error and more obvious effect.

\section{Conclusion}

This paper studies the safety positioning management of three-dimensional underground personnel based on the improved UKF. The WSNs distributed underground are divided into several clusters by clustering method. Each cluster has a certain number of sensors, which can communicate with each other, keep the consistency of estimation, and send data to $\mathrm{CH}$ node. Complex interference is considered as a part of process noise. In order to improve the utilization of sensor resources, event triggering mechanism is proposed. Simulation results show that the improved UKF algorithm is effective under the condition of complex interference.

\section{References}

1. W. Chen, X. R. Jiang, X. Li, J. Gao, X. Z. Xu and S. F. Ding. Measurement, 46:8, 2335 (2013)

2. K. S. Chen, C. Q. Wang, L. Q. Chen, X. X. Niu, Y. Zhang and J. X. Wan. Safety Science, $124(2020)$.

3. J. S. Zhang, J. Fu, H.Y. Hao, G. Fu, F. C. Nie, W.Y. Zhang, Process Safety and Environmental Protection, 136, 78 (2020)

4. M. Yao, Y. X. Fang, W. L. Tang and J. J. Zhou, Safety Science, 128 (2020)

5. A.A. Ansari, P. Gera, B. Mishra and D. Mishra, Indian Academy of Sciences, 45:98 (2020)

6. Y. Wang, L. S. Huang, and W. Yang. Journal on Wireless Communications and Networking (2010)

7. C. L. Zhang, Y. H. Fu, F. M. Deng, B. Q. Wei and X. Wu, Electronics, (2018). 
8. G. B. Zhou, Z. C. Zhu, P. Zhang and W. Li. Computer Communications, 81, 43 (2016)

9. K. Zhou, Y. Teng, D. Zhang and W. A. Zhang, 2019 Chinese Automatic Control Society and John Wiley \& Sons Australia, 1 (2019)

10. W. A Zhang, S. Liu, and L. Yu, IEEE Transactions on Circuits and Systems, 61:5 (2014)

11. H. L. Lin, S. L. Sun, Automatica, 101, 128 (2019)

12. L. Li and Y. Q. Xia, IEEE Transactions on Automatic Control, 58:12 (2013)

13. X. Yang, W. Zhang, B. Chen and L. Yu, 13th IEEE International Conference on Control and Automation (ICCA), 254 (2017)

14. X. Z. Bai, Z. J. Zhang, L Liu, X. J. Zhai, J. Panneerselvam and L. J. Ge, IEEE Access, 7 $28826(2019)$

15. W. Dargie, IEEE Sensor Letter, 30:8, 1-4. (2019)

16. X. Z. Bai, L. Liu, M. Cao, J. Panneerselvam, Q. Sun, and H. Wang, IEEE Access, 5, $13286(2017)$

17. J. Xiong, L. Shu, Q. Wang, W. Xu and C. Zhu, IEEE Access, 5, 379 (2016)

18. X. Z. Bai, Z. D. Wang, L. Zou, and C. Cheng, IEEE Transactions on Industrial Electronics, 65:12, 9687 (2018)

19. Y. C. Yang, J. Z. Li, L. Zhan, Computer Measurement and Control, 22:2 (2014)

20. H. Tan, B. Shen and Q. Li, IEEE Chinese Control Conference (2017)

21. L. Li, D. D. Yu, Y. Q. Xia and H. J. Yang, International Journal of Robust and Nonlinear Control (2017)

22. Y. Liu, Z. D. Wang and D. H. Zhou, Neural Networks the Official Journal of the International Neural Network Society (2018) 